\title{
Geospatial Based Information System Development in Public Administration for Sustainable Development and Planning in Urban Environment
}

\author{
Georgios N. Kouziokas ${ }^{*}$
}

\begin{abstract}
It is generally agreed that the governmental authorities should actively encourage the development of an efficient framework of information and communication technology initiatives so as to advance and promote sustainable development and planning strategies. This paper presents a prototype Information System for public administration which was designed to facilitate public management and decision making for sustainable development and planning. The system was developed by using several programming languages and programming tools and also a Database Management System (DBMS) for storing and managing urban data of many kinds. Furthermore, geographic information systems were incorporated into the system in order to make possible to the authorities to deal with issues of spatial nature such as spatial planning. The developed system provides a technology based management of geospatial information, environmental and crime data of urban environment aiming at improving public decision making and also at contributing to a more efficient sustainable development and planning.
\end{abstract}

Keywords: Geographic information systems; Environmental information; Management information system; Public administration; Sustainable development and planning; Urban data.

\section{Introduction}

Information and Communication Technologies (ICT) has totally changed the traditional framework that have been previously applied by the governmental authorities for adopting sustainable strategies in public management. Previous researches proposed several kinds of information systems for supporting decision making in public administration (Kouziokas, 2016; Chen, Boudreau \& Watson, 2008).

European Union has legislated several rules for computerized information in environmental management and public administration in order to make them available easily accessible to the public through electronic databases (Council Directive 90/313/EEC). European Union Members have complied to these rules and by legislating several laws and regulations (in Italy: Presidential Decree No. 357 (1997), in Spain: Royal Decree No. 1997 (1995)). Considering the increased needs of public administration for collecting and managing several kinds of information indecision making and sustainable planning it becomes necessary for the authorities to utilize an

${ }^{1}$ University of Thessaly, School of Engineering, Department of Planning and Regional Development, 38334, Pedion Areos, Volos, Greece.

*Corresponding Author. 
information system in public management tactics.

Information and Communication Technologies (ICT) can facilitate decision making by retrieving and elaborating key information from the developed database in order to modify and adjust the environmental and urban planning and sustainable management strategies. Several application frameworks have been proposed by researchers for effective management and sustainable development in public administration (Covell, 2016). Information systems have been studied for their applicability in public management decision making by several researchers focusing on the differences between public and private sector context (Bozeman \& Bretschneider, 1986).

Kouziokas (2016), proposed a technology - based sustainable management framework by using continuously updated information derived from an environmental management information system by taking into consideration multiple factors such as spatial data, environmental data, financial data and human resources information.

Chen (2013), proposed an information system based on modern information technology for urban planning by taking into consideration public participation practices for public management.

Cordella \& Iannacci (2010) studied the e-Government enactment framework for applying information systems in the public sector by investigating the logics incorporated in the design of e-Government technologies and by proposing a framework as a theoretical approach for studying the complexity of the factors that influence the adoption of e-Government policies.

Niu, Lu \& Khan (1993) proposed a conceptual framework for adopting spatial systems in sustainable development. The proposed framework includes the development of suitable methodologies for the evaluation of sustainable development at national and regional scales, providing the available information and options to decision makers at various fields.

Coenen, Benneworth \& Truffer (2012) have studied sustainability transitions toward a spatial dimension by developing a conceptual framework for understanding the role of geospatial information in sustainability transitions and analyses.

Also, strategic spatial plans were investigated by various researchers that examined the ecosystem services historically in various cities of the world operationalizing an ecosystem-based approach as a tool for better coexistence of the human society and the ecosystem (Wilkinson, Saarne, Peterson \& Colding, 2013; Folke, et al., 2011).

The developed spatial information system and the conceptual framework proposed by this paper regarding the technology based management in public administration can facilitate decision making process in the direction of sustainability, taking into consideration several factors derived by continuously updated computerized information kept in the information system's relational database.

\section{Materials and methods}

\subsection{Designing the spatial information system}

Multiple factors have been taken into consideration for designing the Geospatial Based Information System (GBIS). First of all, the spatial nature of the data is essential 
for spatial planning and management in urban areas. For that reason, every data in the database have spatial references. Also, in the relational database design stage the construction of the database tables and fields include information regarding: environmental information (parks, trees, etc. spatially defined in the city) which is useful in environmental management, transportation data (statistical data, spatial indexes of the transportation infrastructures: bus, train, metro stations, etc.) for transportation management, pollution information (levels of pollutant factors: carbon monoxide, ozone, etc.) that will be helpful in order to take proactive measures to protect public health, infrastructure data (public buildings, schools, etc.) to be used in urban planning, crime data (crime rates of every crime, crime distribution in the urban area, etc.) that will be used in order to take proactive measures to prevent crime.

Figure1. Information of the GBIS.

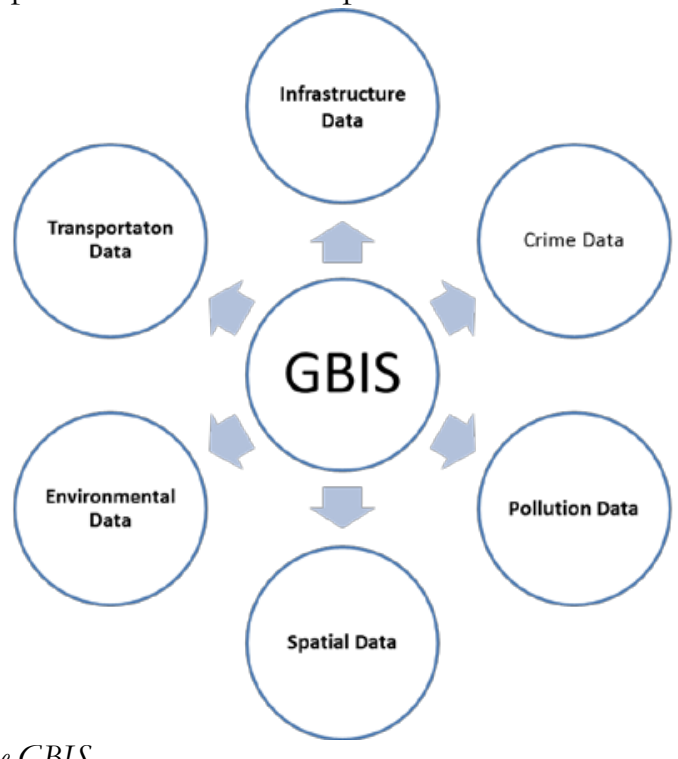

\subsection{Implementation technologies}

The spatial information system was designed using several programming languages, a Database Management System (DBMS) and other technologies. Microsoft SQL Server was utilized as a Database Management System (DBMS) as it is considered as one of the most reliable database management systems. The type of the system's database is a service-based database which allows the access for multiple users and multiple workstations.

Geographic Information Systems were incorporated into the system in order to make possible to the authorities to deal with issues of spatial nature such as spatial analysis and management. Microsoft IIS (Internet Information Server) was utilized as a Web Server. Google maps API was used for manipulating and visualizing spatial information from the database. Visual C Sharp was used as a programming language and Microsoft .NET Framework as a framework for developing the Graphical User Interface (GUI) of the application. 


\section{Results and discussion}

Considering that sustainable development and planning strategies include geospatial analysis and interpretation in order to reveal the most adequate strategies and the degree of their applicability (Bass \& Dalal-Clayton, 2012) a prototype spatial information system for public administration was developed to facilitate public management strategies and decision making process for sustainable development and urban planning.

Geographic information systems were incorporated into the system in order to make possible to the governmental authorities to deal with several issues of spatial nature such as spatial analysis and planning in urban environment.

The proposed framework includes the implementation of a Database Management System (DBMS) for managing spatial and non-spatial information and a Model Base Management System (MBMS) for creating and managing models in decision making.

The development of the present spatial information system is aiming at helping at the construction of a spatial administrative framework that must be delivered in order to facilitate public management strategies in the direction of sustainable development.

This paper proposes a spatial information system that can be used in pubic management in various sectors which are related with spatial information. Pubic administration should take advantage of new spatial technologies and systems like the one proposed in this paper, in order to apply spatially-related decision making strategies in urban environment and promote sustainable development in governmental planning strategies.

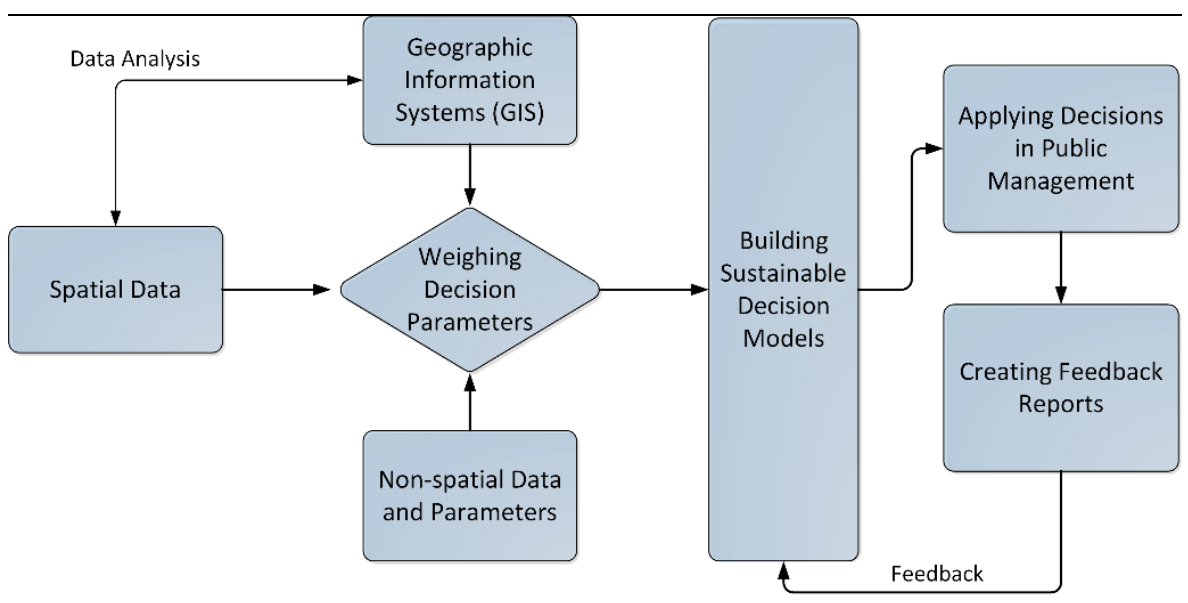

Figure3. The proposed model for spatially enabled decision making process in public management.

Figure 1 shows the proposed conceptual framework by using the developed spatial information system. The collected spatial data regarding the infrastructure, the facilities of the urban area or other kinds of spatial information are inserted to the database of the information system before and after they are processed by GIS software (e.g. ArcGIS). Spatial information is of major importance in order to perform spatially enabled decision 
making processes for sustainable spatial planning in public management. Non-spatial data regarding other important parameters, are also important to be collected in order to build the optimal decision making models. These parameters are also inserted to the system's database and include problem-oriented factors that can be defined and used by the stakeholders in combination with the collected spatial data in order to build the best decision making models by weighing all the parameters and evaluating all the collected data, either primary data or preprocessed data (e.g. spatial data that may be preprocessed by GIS software to produce spatial layers and other useful forms of spatial data).

The advantage of the developed spatial information system compared to other researches (Chen, 2013; Coenen, Benneworth \& Truffer, 2012) is that public stakeholders can take into consideration the spatial nature of the collected information and also multiple factors regarding transportation, urban infrastructure, environmental factors, pollutant factors and crime distribution in order to build management models. Another advantage is that the developed system can manage and manipulate large amount of information and model parameters compared to the traditional decision making tactics.

The proposed spatial information system has great advantages when more complex public management issues must be dealt since facilitates the construction of decision models by taking into consideration spatial and non-spatial factors of various natures.

The proposed spatial information system promotes spatially enabled societies by providing spatial data to the society to be used for multiple causes. In societies which are spatially enabled, spatial data are available for evaluation in order to be used by governments, citizens and private sector for organizing and planning their activities (Roche, 2014; Williamson, Rajabifard \& Holland, 2010).

\section{Conclusions}

Spatial information technologies have an important role in making societies spatially enabled and must be adopted by governmental authorities for developing sustainable cities, by improving sustainable strategies, and promoting spatial-related decision making in governmental management and planning regarding issues of various subjects that affect the quality of human life (Sadeghi-Niaraki, Rajabifard, Kim \& Seo, 2010).

The increasing need for spatial data management in participatory public management has become very important for developing smart and sustainable cities with the citizens in an important role in public decision making (Rambaldi, Kyem, McCall \& Weiner, 2006).

In this paper, a geospatial based information system was designed and developed to provide a more systematic way of solving more complex spatial associated public management issues. The system facilitates the development of decision models by taking into consideration spatial and non-spatial parameters of various natures and can be used to manage a large amount of data in order to facilitate public and environmental management and planning for sustainable development. 


\section{References}

Bass, S., \& Dalal-Clayton, B. (2012). Sustainable development strategies: a resource book. Routledge.

Bozeman, B., \& Bretschneider, S. (1986). Public management information systems: Theory and prescription. Public administration review, 475-487.

Chen, A. J., Boudreau, M. C., \& Watson, R. T. (2008). Information systems and ecological sustainability. Journal of Systems and Information Technology, 10(3), 186-201.

Chen, Y. (2013). Study on Urban Planning Public Participation Information System Based on Modern Information Technology. Journal of Convergence Information Technology, 8(10), 1031.

Coenen, L., Benneworth, P., \& Truffer, B. (2012). Toward a spatial perspective on sustainability transitions. Research policy, 41(6), 968-979.

Cordella, A., \& Iannacci, F. (2010). Information systems in the public sector: The e-Government enactment framework. The Journal of Strategic Information Systems, 19(1), 52-66.

Covell, C. (2016). Sustainable Development for Public Administration: Effective Management Administrative System of the 21st Century Public Administration. Journal of Public Administration and Governance, 6(2). doi:10.5296/jpag.v6i2.9368

Council Directive 90/313/EEC of 7 June 1990 on the freedom of access to information on the environment OJ L 158, [1990] 0056 - 0058.

Folke, C., Jansson, A., Rockström, J., Olsson, P., Carpenter, S. R., Chapin III, F. S., Crépin, A.S., Daily, G., Danell, K., Ebbesson, J., Elmqvist, T., Galaz V., Moberg F., Nilsson M., Österblom H., Ostrom E., Persson Å., Peterson G., Polasky S., Steffen W., Walker B., \& Westley F. (2011). Reconnecting to the biosphere. Ambio, 40(7), 719-738.

Kouziokas, G. N. (2016). Technology-based management of environmental organizations using an Environmental Management Information System (EMIS): Design and development. Environmental Technology \& Innovation, 5, 106-116. doi:10.1016/j.eti.2016.01.006.

Niu, W. Y., Lu, J. J., \& Khan, A. A. (1993). Spatial systems approach to sustainable development: A conceptual framework. Environmental Management, 17(2), 179-186.

Presidential Decree No. 357 (1997). Implementing Directive 92/43/EEC of 21 May 1992 on the conservation of natural habitats and of wild fauna and flora. Official Gazette of the Italian Republic, 248, 5-46.

Rambaldi, G., Kyem, P. A. K., McCall, M., \& Weiner, D. (2006). Participatory spatial information management and communication in developing countries. EJISDC: The Electronic Journal on Information Systems in Developing Countries, (25), 1.

Roche, S. (2014). Geographic Information Science I Why does a smart city need to be spatially enabled?.Progress in Human Geography, 38(5), 703-711.

Royal Decree No. 1997 (1995) on measures to contribute to guaranteeing biodiversity through the conservation of natural habitats and wild fauna and flora. Official Gazette of the Spanish State no. 310.

Sadeghi-Niaraki, A., Rajabifard, A., Kim, K., \& Seo, J. (2010, October). Ontology based SDI to facilitate spatially enabled society. In Proceedings of GSDI 12 World Conference (pp. 19-22).

Wilkinson, C., Saarne, T., Peterson, G. D., \& Colding, J. (2013). Strategic spatial planning and the ecosystem services concept-an historical exploration. Ecology and Society, 18(1), 37.

Williamson I., Rajabifard A.\& Holland P. (2010). Spatially enabled society. In: Proceedings of the FIGURE Congress 2010, Facing the Challenges - Building the Capacity, Sydney. Available at: http://www.fig.net/pub/fig2010/papers/

inv03\%5Cinv03_williamson_rajabifard_et_al_4134.pdf. 